\title{
Functional foods beyond nutrition: therapeutic interventions to combat COVID-19 and other viral diseases
}

\author{
Samudra P. Banik ${ }^{\mathrm{a}}$, Rituparna Banik Ghosh ${ }^{\mathrm{b}}$, Bernard W. Downs ${ }^{\mathrm{c}}$, Sanjoy Chakraborty ${ }^{\mathrm{d}}$, \\ Manashi Bagchie, Tandra R. Chakraborty ${ }^{\mathrm{f}}$ and Debasis Bagchi ${ }^{\mathrm{c}, \mathrm{e}, \mathrm{g}^{*}}$
}

\author{
aDepartment of Microbiology, Maulana Azad College. Kolkata, India \\ ${ }^{b}$ Department of Physiology, Bhairab Ganguly College, Kolkata, India \\ 'Victory Nutrition International, Inc., Dept of R\&D, Bonita Springs, FL, USA \\ ${ }^{\mathrm{d}}$ Department of Biological Sciences, New York City College of Technology/CUNY, Brooklyn, NY, USA \\ eDepartment of Biology, Adelphi University, New York City, NY, USA

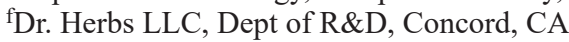 \\ gDepartment of Pharmaceutical Sciences, Texas Southern University, Houston, TX, USA \\ *Corresponding author: Debasis Bagchi, Department of Pharmaceutical Sciences, Texas Southern University, Houston, TX, USA. \\ E-mail: debasisbagchi@gmail.com
}

DOI: $10.31665 /$ JFB.2021.15283

Received: September 26, 2021; Revised received \& accepted: September 30, 2021

Citation: Banik, S.P., Ghosh, R.B, Downs, B.W., Chakraborty, S., Bagchi, M., Chakraborty, T.R., and Bagchi, D. (2021). Functional foods beyond nutrition: therapeutic interventions to combat COVID-19 and other viral diseases. J. Food Bioact. 15: 63-73.

\begin{abstract}
SARS-COV2 has emerged as the second biggest threat to humanity of all times, after the Spanish Flu massacre. Due to its brisk rate of mutation, especially that of the host receptor docking Spike protein, a safe immunization is still questioned by some, and protection or recovery has been dependent largely on immune system competence and overall bio-constitutional strength. In order to ensure optimal performance of the body's immune cells, proper nutrition fortified with functional food ingredients is indispensable. Especially in a scenario where targeted therapeutics against life threatening pandemics like SARS-CoV2 are yet to be invented, formulation of dietary supplements rich in antioxidants, vitamins, and minerals is the need of the hour to promote greater immuno-competence and a heightened immune response; decrease the overall metabolic burden; and restore homeostasis in an infected individual. This review highlights our current understanding and advances made in the regimen of functional foods designed to combat viral diseases together with the shortcomings involved therein.
\end{abstract}

Keywords: SARS-CoV2; Antivirals; Functional food; Nutraceuticals; Healthy immune system.

\section{Introduction}

Viral outbreaks had been the cause of serious concern for human health and well-being since time immemorial. The Spanish flu or the Great Influenza Epidemic of 1918 caused by the H1N1 influenza virus was one such major documented catastrophe that infected about one third's of the world population and took away the lives of at least 50 million people. Since then, the COVID-19 pandemic, has emerged as the biggest threat to human life and civilization with more than 220 million people affected worldwide up to the date of this writing. The pandemic, caused by an enveloped $(+)$ single stranded and non-segmented RNA virus belonging to Coronaviridae family, has currently a global death toll exceeding 4.5 million. This has been the third and most significant attack unleashed on humankind from the betacoronaviridae family following the outbreaks of SARS-CoV-1 in 2003 and MERS-CoV in 2012. The other four human coronaviruses, which resulted in mild symptoms, were HKU1, NL63, OC43 and 229E (Cui et al., 2019). In order to combat these recurrent viral infections, aside from developing natural immunity from getting COVID-19, the best possible way is to prime our immune system with the specific antiviral 


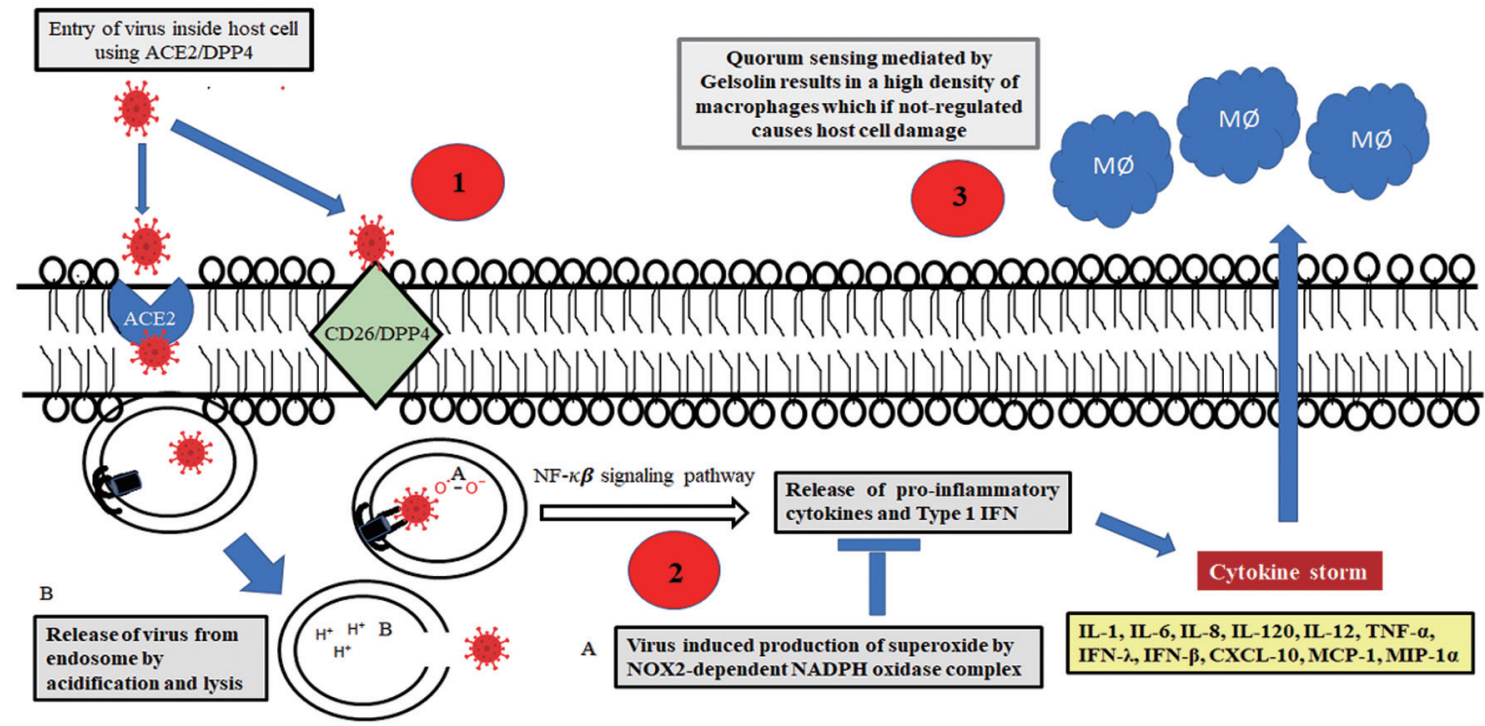

Figure 1. Potential targets of therapeutic interventions to arrest viral progression: As shown in numbered red circles 1 . Therapeutics to sequester and deplete DPP4, a potent receptor of SARS-coronavirus 2. Drugs targeted against NOX2-depenedent NADH oxidase complex to prevent superoxide mediated oxidation of TLR7 and subsequent inhibition in secretion of IFN 3 . Therapeutics to modulate the expression of gelsolin and hence regulate the density dependent phenotype of macrophages to minimize host damage arising out of immune response.

antibodies is through immunization. However, the development of a vaccine against SARS-CoV-2 has been a challenging task due to incomplete understanding of the life cycle, epidemiology, and specific immune responses directed against the virus (Ahmed et al., 2020). Moreover, emerging evidence indicates that there is a high probability that the efficacy of vaccines will decline over time due to rapid changes in what is believed to be caused by the genetic makeup of the virus. Therefore, although getting immunized is critical in maximizing protection against the viral infection, vaccination cannot safeguard a person completely from acquiring the viral disease. Under these circumstances, boosting our own innate immune response forms the foundation to sufficiently bolster competent resistance to viral infection. In order to possess a healthy immune system, maintenance of a lifestyle that promotes an aerobic metabolism with optimal nutrition is of paramount importance.

Viruses enter our cells through specific entry points utilizing defined molecular targets. Therefore, in addition to consumption of a balanced diet fortified with adequate minerals and vitamins, it is also essential at the same time to identify nutraceuticals and functional foods that can be administered in addition to the staple diet. These are supposed to act as therapeutic interventions to help blocking viral entry points and augment the immune response (Figure 1).

\section{Identifying potential check points of viral infections for therapeutic intervention}

Viruses enter host cells via several mechanisms including endocytosis, macrocytosis, pinocytosis, and phagocytosis. They can also fuse at the plasma membrane and spread within the host via cell-to-cell fusion or syncytia. Generally, alpha- and beta-coronaviruses employ angiotensin-converting enzyme 2 (ACE2) receptors for infecting lung epithelial cells (Li et al., 2003). ACE2 is a transmembrane carboxypeptidase of the Renin-Angiotensin System implicated in vasodilation following hypertension and related ailments (Tikellis and Thomas, 2012), which acts as a receptor for the viral Spike protein (Shang et al., 2020). However, exceptions to this general route have also been reported frequently. Camel alphacoronaviruses, human alpha-coronavirus 229E (along with porcine delta-coronavirus) are known to infect host cells by docking onto corresponding Aminopeptidase $\mathrm{N}$ receptors (Li et al., 2020). Additionally, canine respiratory beta-coronavirus is known to employ Human Leukocyte Antigen Class 1 (HLA-1) as receptor for host cell entry (Szczepanski et al., 2019).The coronaviruses are made up of four structural proteins, namely, the spike (S), membrane (M),envelop (E) and nucleocapsid (N) proteins. The spike protein of SARS-CoV-2 is the specific docking ligand of ACE2, which consists of two domains; a pleated S1 domain or Receptor Binding Domain, and a helical S2 domain which enables the virus to fuse with host cell membrane. In SARS-CoV-2 and a few other coronaviruses, there is a stretch of amino acids (PRRARS/V) between the $\mathrm{S} 1$ docking and $\mathrm{S} 2$ fusion domain which serves as a recognition site for the host protease furin. Cleavage by furin occurs as a natural defence mechanism of the host, but acts in the favour of the virus by exposing the access of the S2 fusion domain to the host membrane for fusion and entry. This also explains why infection by SARSCoV-2 occurs selectively for the ciliated epithelial cells of the lungs where there is an abundance of furin proteases. The $\mathrm{S}$ gene corresponding to the spike protein is one of the hypervariable spots of the viral genome (Wen et al., 2020), which enables it to quickly change and successfully use a number of zoonotic carriers as natural reservoirs and intermediate hosts before infecting humans. This also explains the significantly faster rate of mutation of SARS-COV2 and appearance of its variants. In addition to ACE-2, the S1 domain of the spike glycoprotein is also known to interact with the human CD26 (also known as Dipeptidyl Peptidase IV or DPP4), a multifunctional transmembrane type II glycoprotein, expressed constitutively on several cell types including epithelial cells, endothelial cells, and fibroblasts, as well as many immune cells, including T, $\mathrm{B}$, and natural killer lymphocytes, and macrophages. There is also a soluble counterpart of the molecule in plasma and its enhanced expression has been implicated in down regulating inflammatory response (Busso et al., 2005, Sargiacomo et al., 2020). 
CD26 is often hijacked by viruses during infection and subsequent occupancy of the cellular machinery, and therefore forms a potential target molecule for designing anti-viral therapeutics (Vankadari and Wilce, 2020). After successfully mediating membrane fusion, the viral RNA in the pulmonary alveolar epithelial cells is endocytosed and released into the cytosol by lysis of the endosomal membrane with subsequent intracellular release of viral contents. Host immune response is initiated at this point as trapped single stranded viral RNA primes the Toll Like Receptor 7 (TLR7) on the endosomal membrane thereby signalling the release of Type 1 interferon (Diebold et al., 2004). Thereafter, the virus synthesizes a negative strand RNA from the pre-existing single-strand positive RNA. The negative strand RNA serves to produce new strands of positive RNAs which are deployed in translation. Assembly of new virion particles takes place in the cellular endoplasmic reticulum with the viral $\mathrm{N}$ and $\mathrm{M}$ proteins from where they are exocytosed into the extracellular space via Golgi derived vesicles. The new viral particles can then initiate a fresh round of infection of the adjacent epithelial cells or infect other individuals through burst of respiratory droplets.

Coronaviruses and a wide group of other RNA viruses including Sendai virus, HIV, rhinovirus, human meta pneumonia virus, respiratory syncytial virus, human para influenza virus, Dengue virus, etc., have adopted a clever strategy to immediately suppress the release of interferon. These viruses induce production of superoxides in the endosomal compartment of human alveolar macrophages by NOX2-dependent NADPH oxidase complexes (Sindona et al., 2021). The generated hydrogen peroxide oxidises the Cys98residue on TLR7 that permanently blocks transmission of signal for type 1 interferon production. This was demonstrated in both mutant macrophages deficient in NOX2 activity, and in cell lines with a targeted NOX2 inhibitor (gp91ds-TAT) where the level of type 1 interferon was markedly higher in response to RNA virus infection. Therefore, novel NOX2 inhibitors can act as effective therapeutic agents to arrest viral progression.

Cardinal signs of COVID-19 infection are initiated from this phase onwards when the virus migrates to the upper respiratory tract and fever accompanied with dry cough begins. The immune response also heightens at this phase with the release of $\mathrm{C}-\mathrm{X}-\mathrm{C}$ motif chemokine ligand 10 (CXCL-10) and interferons (IFN- $\beta$ and IFN- $\lambda$ ) from the virus-infected cells (Tang et al., 2005), chiefly the lung pneumocytes. Cytokines attract and recruit a battery of immune cells including a large number of macrophages, neutrophils, $\mathrm{CD}^{+}$helper $\mathrm{T}$ cells, and $\mathrm{CD} 8^{+}$cytotoxic $\mathrm{T}$ cells. The immune response is further augmented by the large scale release of proinflammatory cytokines including interleukins (IL-1, IL-6, IL-8, IL-120 and IL-12), tumour necrosis factor- $\alpha$ (TNF- $\alpha$ ), IFN- $\lambda$, and IFN- $\beta$, CXCL-10, monocyte chemo-attractant protein-1 (MCP-1), and macrophage inflammatory protein- $1 \alpha$ (MIP-1 $\alpha)$. The events collectively lead to the elicitation of the characteristic "cytokine storm" and many cells die out of lung injury. In more extreme cases, fluid starts accumulating inside the lung cells and there is loss of both type 1 and type 2 pneumocytes; if left untreated, these complex events can gain pathological momentum and morph into the development of Acute Respiratory Distress Syndrome (Xu et al., 2020), the most significant cause behind COVID-19 inflicted death. A recent significant finding has indicated that the macrophage population at the site of inflammation is regulated by a quorum sensing phenomenon, which limits the extent of inflammatory response and minimizes host damage as a consequence of cytokine storm. The secreted form of the actin severing protein gelsolin, has been identified as the key auto-inducer of the quorum sensing phenomenon. Gelsolin can therefore be another potential target for developing new generation therapeutics for uncontrolled immune proliferation (Sharma et al., 2021).

\section{Role of diet in establishing a healthy gut microbiome and an} optimally functioning immune system

It has been unequivocally demonstrated that optimal nutrition is vital for keeping ourselves healthy. Nutritional deficits can adversely affect the immune system and hence curb the potential to fight microbial infections (Chandra, 1996). Specific components of nutrients are implicated in activation of immune functions through modulation of gene expression and signalling molecules (Valdés-Ramos et al., 2010). In addition to other numerous benefits, dietary ingredients can also influence immune responses through their effects on gut microbiota composition (Singh et al. 2017); the evolution and development of our immune system owes a lot to our healthy microbiome and therefore these two have been intricately associated with each other since the birth of a child. This is best portrayed by regulatory $\mathrm{T}\left(\mathrm{T}_{\text {reg }}\right)$ cells, a subset of $\mathrm{T}_{\mathrm{H}}$ cells, which mediate immune tolerance to self-antigens as well as to the antigenic determinants of commensals colonizing the human microbiome (Cebula et al., 2013).

Babies feeding on breast milk develop a solid foundation of their immune response compared to those consuming formula milk. Apart from its nutritive constituents, mother's milk contains plenty of bioactive components including lysozyme, sIgA, alphalactalbumin, lactoferrin, free oligosaccharides, complex lipids, and glycoconjugates, which play a significant role in the maturation of newborn immunological responses (Lazar et al., 2018). A major glycoprotein of milk, k-casein, is proteolytically cleaved to generate glycomacropeptides, which prevents the growth of pathogens on gut epithelial cells (Gordon et al., 2012). Mother's milk also contains lactoferricin, a potent antimicrobial agent that combats pathogen colonization. Several key interacting factors between malnutrition and diseases have been delineated and therefore many detrimental effects seen in under-nourished children can be controlled by prompt nutritional supplementation (Schuetz et al., 2019).

The Mediterranean diet has been one of the most sought after food habits globally due to its proven effects in maintaining a healthy lifestyle and achieving wellness (Trichopoulou et al., 2003). It is rich in vegetables, fruits, legumes, nuts, beans, cereals, grains, fish, and unsaturated fats, and generally includes a bare minimum of meat and dairy foods. Due to the presence of high levels of polyphenols, foods comprising a typical Mediterranean diet exhibit pleiotropic health-augmenting effects, especially with regards to alleviation of cardiovascular troubles and in the treatment of type- 2 diabetes. Consumption of a plant and fish rich diet also benefits immensely the health of our gut microflora due to the presence of gut friendly dietary fibers and unsaturated fatty acids that have often been found to reverse dysbiosis caused by frenzied lifestyle. For example, strict adherence to a Mediterranean diet pattern resulted in a significant decrease in obesity of individuals habitually fed Western diets (Nagpal et al., 2019).

In spite of consumption of naturally nutritious diets fortified with all proximate and protective principles of food that can supposedly augment our immune system and enable us to stay strong and healthy against the menace of infectious diseases, over recent years, outbreak of deadly microbial pathogens have jeopardized human health. Consumption of nutritive foods alone have been found wanting in many cases to safeguard us. This has necessitated the introduction of functional foods and nutraceuticals as a figurative 'shot in the arm' for boosting our immune response against the onslaught of the deadly viruses and other pathogens. 


\section{Nutraceuticals and functional foods as indispensable boost ups of the immune system}

Natural compounds and edible food ingredients contain many bioactive components that are capable of providing health benefits beyond the traditional nutritional value of food. These components have been ascribed the term "functional foods" or the dietary items that in addition to providing nutrients and energy, benefit certain targeted functions of the body (Nicoletti, 2012), possess the potential to boost immune response (López-Varela et al., 2002), and also reduce the risk of diseases (Martirosyan and Singh, 2015). The term is sometimes used synonymously with "nutraceuticals", which are rather extracted bioactive components of functional foods that can be converted for use in edible pills or capsules, or as fortified foods, dietary supplements, or herbal products marketed commercially.

Over last few decades, a large number of natural reservoirs of functional food components have been discovered including spices like black pepper, turmeric, ginger and garlic, fruits like pomegranate and elderberry, and other edible medicinal plants such as liquorice, which are reservoirs of immunomodulatory and anti-viral agents (Yang et al., 2020). For example, Bromelain, a cysteine protease, obtained from the pineapple stem (Ananas comosus) has traditionally been known for the management of trauma (Jain et al. 2012). In addition, bromelain has also been implicated in the inhibition of cyclooxygenase and hydrolysis of bradykinin, thus alleviating COVID-19 symptoms.

In spite of these sporadic but significant successes, scientists are yet to get confirmatory evidence regarding the efficacy of many more food plants in human systems in addition to complete elimination of any toxic side effects. The important biomolecules which are found in abundance in plant extracts are as given in the following sub-sections.

\subsection{Polyphenols}

These are plant secondary metabolites providing a range of protective functions against ultraviolet radiations, infectious diseases, and oxidative stress. Most of them have planar and fused phenolic rings with hydroxyl groups as substituents. They can be classified into phenolic acids, flavonoids, polyphenolic amides, and other polyphenol compounds (including stilbenes or lignans) (Annunziata et al., 2020). Polyphenols are proven inhibitors of inflammation and prevent expression of pro-inflammatory genes (Yahfoufi et al., 2018). Polyphenols have been found to be effective against a broad range of viruses including Epstein-Barr virus (Yiu et al., 2010), enterovirus 71 (Zhang et al., 2015), herpes simplex virus (HSV) (Faith et al., 2006), influenza virus (Lin et al., 2015), and other virus-causing respiratory tract-related infections (Zang et al., 2011). Most of the polyphenols exert their activity especially as anti-virals in a synergistic manner. For example, a crude extract prepared from Sambucas nigra was able to inhibit viral replication successfully in a Vero cell line and led to alteration of viral structure (Chen et al., 2014).

\subsection{Molecular mechanism of action of polyphenols}

Quite a few mechanisms to explain the antiviral properties of these compounds have been proposed. For example, polyphenols from Broussonetia papyrifera were found to inhibit the proteases of MERS/SARS-COV2 thereby effectively blocking the spread of the virus. Another commonly occurring polyphenol is trans-resveratrol, or 3,5,4'-trihydroxy-trans-stilbene, first isolated as a bioactive com- ponent from the roots of Polygonum cuspidatum (Lin et al., 2015) (common name is Chinese knotweed) and subsequently discovered to occur in abundance in various types of grapes, berries, nuts, etc. This polyphenol is popular as a powerful antioxidant and prevents development of inflammatory responses. It has been found to be upregulated under exposure to UV radiation, ozone, and in response to fungal infections (Pannu and Bhatnagar, 2019).In addition, resveratrol has been demonstrated to be a potent inhibitor of upper respiratory tract viral infections. Resveratrol directly interferes with the replication of influenza virus by blocking the nuclear to cytoplasmic translocation of Ribonucleoprotein particles (Palamara et al., 2005). In case of infection by coronaviruses, resveratrol has been found to significantly increase the survival rate of virus infected cells in the body by reducing their frequency of apoptosis (Lin et al., 2017). The antiviral properties of resveratrol are augmented by its strong immune modulating capabilities. Resveratrol alters cytokine and chemokine levels to down-regulate ROS-mediated inflammatory responses and leads to suppression of the NF- $\mathrm{KB}$ mediated pathway of activation of proinflammatory response (Meng et al., 2020). In addition, resveratrol administration has also been observed to result in upregulation of the IFN $\beta$ gene for arrest of viral replication (Lin et al., 2015). However, in spite of so many health augmenting roles of resveratrol, its therapeutic application has been restricted due to poor solubility and low bioavailability (Shaito et al., 2020).

\subsection{The basis of antioxidative potential of green tea}

Consumption of green tea had become popular globally over the last few decades owing to its proven role as a strong antioxidant. Green tea is made from the leaves of Camellia sinensis and the active components responsible for its antioxidative property are catechins. Catechins are also plant secondary metabolites belonging to the class of hydroxyflavans that have a flavan-3-ol skeleton and its substituted derivatives. Catechins comprise about $10 \%$ of the dry weight of green tea leaves and include (-)-epigallocatechin gallate (EGCG), (-)-epigallocatechin (EGC), (-)-epicatechin gallate (ECG) and (-)-epicatechin (EC) as the major constituents with EGCG accounting for about $50 \%$ of the total amount of catechins in green tea (Reygaert, 2018). EGCG has been reported to possess many different pharmacotherapeutic properties including antioxidative, antibacterial, and antiviral roles (Song et al., 2005). EGCG serves as a potent inhibitor of HIV replication (Fassina et al., 2002) as well as an agglutinating agent of influenza viruses (Nakayama et al., 1993). Antiviral activity of catechins are believed to be due to their inhibition of host-virus membrane fusion by prevention of acidification of the endosomal compartment (Imanishi et al., 2002).

\subsection{Probiotics}

The role of intestinal microflora in maintaining the overall health of the individual has been established beyond arguments. However, much like our own organs, the consortium of gut microbes are also susceptible to occasional dysbiosis resulting in altered functionalities with undesirable effects. Probiotics are live microbes that can supplement and replenish the ailing gut flora and restore homeostasis. Gut commensals connect and communicate with two major organs of the human body to ensure maintenance of physiological homeostasis; with the brain via the gut-brain axis (Carabotti et al., 2015) and with the lung via the gut-lung axis (Dang and Marsland, 2019). Much like the resident gut microbes, probiotics also can modulate many host immune responses (Frei et al., 2015) and thereby curb the infectivity of a lot of viral pathogens, especially those in- 
volved in respiratory tract infections (Hao et al., 2015). Probiotics have already been recommended as a mitigation strategy for a weakened immune system following COVID-19 infection (Mirzaei et al., 2021) where gut microfloral dysbiosis with significant reductions in Lactobacillus and Bifidobacterium have been seen (Xu et al. 2020). They have been associated with increased expression of mucous glycoproteins to strengthen the epithelial barrier against viral invasion. Probiotics are also implicated in resurrection of tight junction complexes following virus inflicted damage through increased expression and redistribution of zonula occluden $(\mathrm{ZO}-2)$ proteins and protein kinase C (PKC) (Yi et al., 2018).

\subsection{Molecular mechanism of the action of probiotics}

Although the exact mechanism of probiotic based prophylaxis of viral infections still remains to be delineated, these microbial strains are believed to exert their immunomodulatory effects via interaction of the bacterial constituents like peptidoglycan, lipoteichoic acid, and nucleic acid with their cognate Toll Like Receptors as well as muramyl dipeptide, which binds to the Nod-like receptors (Pimentel-Nunes et al., 2010) and subsequent modulation of $\mathrm{T}_{\text {reg }}$ cells, $\mathrm{T}_{\mathrm{H}} 17$ cells, and type 3 innate lymphoid cells (Kanauchi et al., 2018). Probiotic strains also boost type I interferon levels for enhanced viral infection alarm and increase the number and activity of the immune arsenal comprised of NK cells, T cells, and levels of circulating antibodies. These are also implicated in modulating the levels of proinflammatory and immunoregulatory cytokines leading to enhanced viral clearance with minimal bystander damage to lung cells. Collectively, the probiotics restrict viral replication by a) enhancement of the intestinal epithelial barrier b) attaching to and sequestering viruses c) by secreting antiviral components such as bacteriocins and hydrogen peroxide d) by induction of basal level nitric oxide (NO) generation by host cells e) by activation of macrophages and dendritic cells $\mathrm{f}$ ) by inducing CD8+ T cells into Cytotoxic T Lymphocytes and g) by inducing differentiation of $B$ cells by $T_{\mathrm{H} 2}$ cells (Tapiovaara et al., 2016). Although rare incidents of probiotic-associated bacteremia and fungaemia have been reported in a few immunocompromised patients (Bertelli et al., 2015), probiotics are generally safe (Dermyshi et al., 2017).

\subsection{Prebiotics}

To keep our gut microbiota happy and rejuvenated, they have to be fed with specific nutrients that are not absorbable by our gut, but tailormade for these microbes. The gut microbiota thrives on certain plant derived dietary fibers, which human enzymes are incapable of digesting. These dietary fibers are collectively known as prebiotics. Numerous common fruits and vegetables including apples, artichokes, bananas, berries, legumes, tomatoes, asparagus, etc. are enriched in prebiotic fibres including fructans, oligosaccharides, arabinooligosaccharides, isomaltooligosaccharides, xylooligosaccharides, resistant starch, lactosucrose, lactobionic acid, galactomannan, psyllium, polyphenols, and polyunsaturated fatty acids, among others (Guarino et al., 2020). In addition to providing essential nutrients to the gut microbes, the prebiotics also benefit our body in a lot of other ways including facilitating absorption of calcium (Scholz-Ahrens et al., 2007), regulating the glycemic index (Connolly et al., 2012), boosting digestion (Cummings et al., 2001), and keeping the epithelial cell lining healthy (Carlson et al., 2018). New insights have also suggested the beneficial role of prebiotics in management of chronic gut disorders such as Irritable Bowel Syndrome (Wilson et al., 2019).

\subsection{Antioxidant vitamins}

Micronutrients, comprising vitamins and minerals, are named so due to the fact that requirements by our body are in relatively smaller or trace amounts. However, they are as important as the primary nutrients and their deficiency leads to impairment of many key metabolic reactions and biochemical pathways as well as malfunctioning of the host immune response (Opara, 2002). They have a significant role to play in maintaining the functionality of both innate and adaptive immune responses and micronutrient homeostasis is integral to the sustenance of a healthy immune system (Wintergerst et al., 2007). Some vitamins like A, C, E, flavonoids, and carotenoids are readily obtainable from the diet and therefore can function relentlessly in neutralizing oxidative free radicals. A loss in the balance of these elements can make a person susceptible to infection and diseases, and supplementation, on the other hand, can augment the recovery process, especially from viral infections (Jayawardena et al., 2020).

\subsection{Vitamin $D$ as a model vitamin with a functional food tag}

A multidimensional vitamin in terms of therapeutic potential is Vitamin D, also referred to as "calciferol". It is a fat-soluble vitamin existing in different forms that is naturally present in a few foods, but mostly produced endogenously by lower layers of skin epidermis by a chemical reaction driven by the reaction of photons of sunlight with cholesterol (Holick et al., 1980). Hence, the major forms found in human circulation are Vit D3 (cholecalciferol) and D2 (ergocalciferol) (Bikle, 2014). Vitamin D obtained from food sources or synthesized in presence of sunlight is not biologically active. It is activated by two successive enzymatic hydroxylation events occurring respectively in the kidney and the liver, to yield 1,25-dihydroxyvitamin D (Bikle et al., 2002). Vitamin D is involved regulating many physiological processes inside the body including reabsorption of calcium and magnesium, which are also involved as $\mathrm{pH}$ buffers, mediating bone and extra-skeletal metabolism, regulating cardiovascular homeostasis, and most significantly modulating immunological responses of our bodies (Christakos et al., 2016). Vitamin D is also implicated in a marked reduction in pro-inflammatory cytokines thus decreasing the probability of a cytokine storm (Martineau et al., 2017) thereby reducing the need for prolonged inflammatory events. A recommended dose of vitamin D3 ranges from 2,000 to 10,000 IU/day.

\subsection{Molecular basis of action of Vitamin D}

Vitamin D enters inside the cell and exerts its effect by binding to its cognate nuclear receptor VDR. VDR exists as a heterodimer with an isoform of the retinoid $\mathrm{X}$ receptor (RXR). Ligand triggered conformational change of VDR-RXR heterodimers induces dissociation of co-repressor proteins such as nuclear receptor co-repressor (NCoR) and binding of the VDR-RXR heterodimer to the vitamin D response elements (VDRE) on the promoter regions of antimicrobial peptides (AMPs). These include human cathelicidin (human cationic antimicrobial protein; hCAP18) and human b-defensin-2 (hBD-2) (Beard et al., 2011). AMPs are localized on mucosal and epithelial layers and constitute one of the primary defenses against pathogens. On the other hand, epidermal expression of 1,25(OH)2D3 leads to expansion of CD4+ and CD25+ regulatory T cells (Loser and Beissert, 2009), and suppresses $\mathrm{T}$ cell proliferation. This is implicated in moderation of heightened immune response after the viral infection subsides to minimize host damage. 


\subsection{Role of micronutrients}

Micronutrients also play an integral role in the alleviation of pathogen inflicted damage and restoration of homeostasis during recovery after viral replication. However several factors actually regulate the efficacy with which they can augment the recovery process; these include the kind of pathogen; the administered dose of the micronutrient; as well as the age, genetic background, and nutritional status and lifestyle of the patient, i.e. epigenetic factors (Lange, 2021). Immunosenescence or immune dysfunction during aging also profoundly affects the ability of the body to respond to nutrient functions (Yaqoob, 2017). The pharmacotherapeutic success of micronutrients is dependent upon a synergistic response of a wide range of components rather than administration of individual nutrients in isolation.

Zn deficiency has been implicated with reduced antibody production, and impaired activity of the innate immune system with a simultaneous decline in neutrophil population and secretion of cytokines by monocytes (Ibs and Rink, 2003). Suboptimal levels of this element have also been found to be associated with suppressed production of thymic hormones resulting in significant decrease in the number of peripheral and thymic T cells. Thymulin is a nonapeptide hormone responsible for inducing differentiation of $\mathrm{T}$ cells (Bach and Dardenne, 1989). Its active structure requires zinc and hence zinc deficiency also affects $\mathrm{T}$ cell proliferation.

\subsection{Antiviral properties of Zinc and the mechanism involved}

Zinc has also demonstrated antiviral properties, which is probably executed through metallothioneins (MT), a family of low molecular weight, cysteine-rich proteins that mediates sequestration and release of $\mathrm{Zn}^{2+}$ and are also involved in oxidative response, apoptosis, and immune responses (Subramanian and Deepe, 2017). Metallothioneins may either act directly by sequestering Zn2+ away from the viral metalloproteins or indirectly by inducing Interferon gamma signalling. Zinc has also sometimes been used in conjunction with standard antiviral therapy where it has synergistically inhibited the folding and/or activity of viral enzymes and resulted in inhibition of viral replication. For example, the element has been shown to inhibit the template binding of RNA Dependent RNA Polymerase; arrest the replication of coronaviruses (Te Velthuis et al., 2010); inhibit the protease mediating viral polyprotein cleavage in Encephalomyocarditis virus (Butterworth and Korant, 1974); and inhibit RNA polymerase in Hepatitis C virus (Ferrari et al., 1999), DNA polymerase in Herpes Simplex virus (Fridlender et al., 1978), and many more. Zinc supplementation seems to have prospect in the prophylaxis and treatment of COVID-19 (Rahman and Idid, 2021). Accordingly, therapeutic trials of free zinc in the forms of creams, lozenges, and supplements had been initiated sporadically but most of them are yet to get approval for commercial applications.

\subsection{Importance of selenium as an antiviral micronutrient}

Alongside zinc, selenium is also an important micronutrient implicated in maintenance of immune health (Rayman, 2000) and therefore effective in antiviral therapy. Selenium supplementation has been known for its immune-supporting effect, which includes enhancement of activated $\mathrm{T}$ cells (cytotoxic lymphocytes) and proliferation of NK-cell activity (Kiremidjian-Schumacher and Roy, 1998). The element has also been found to be effective as an im- munity booster in combination with certain vitamins such as $\mathrm{D}$ and E (Delesderrier et al., 2019). When administered in conjunction with phytoncides (present in onions), selenium results in increased T lymphocyte proliferation (Ru-duan et al., 1992) In addition, selenium can also prevent the formation of thrombosis in the blood vessels. Blood coagulation disorders leading to the formation of tiny clots constitute one of the significant reasons for death of patients with COVID-19 (Fogarty et al, 2020). Therefore, use of sodium selenite may reduce the formation of blood clots and increase the chances of patient's survival. Selenium is a co-factor in glutathione peroxidase and can be reduced from the tetravalent selenite to the divalent cation ( $\mathrm{Se} 2+$ ) thus acting as a powerful oxidant. This oxidizing capacity of selenite is exploited in its antiviral activity as selenite readily oxidizes the sulfhydryl groups in the active site of the viral protein disulphide isomerase (PDI) crosslinking them to inactive disulphide. This effectively stops the viral spike protein from engaging in exchange reactions with disulphide groups of cell membrane proteins and thus prevents viral entry into the healthy cell cytoplasm (Kieliszek and Lipinski, 2020).

\subsection{Spices as functional foods}

Plants are rich sources of flavonoids, antioxidants, polyphenols, coumarins, and steroids that help in boosting the immune system (Messina et al., 2020, Somerville et al., 2016). Spices can be produced from any part of the plant, for example the leaf (e.g., bay leaf), buds (clove), bark (cinnamon), root (ginger), berries (grains of pepper), seeds (cumin), or even the stigma of the flower (saffron). Allicin, capsaicin, curcumin, gingerol, mustard oil, piperine, and quercetin glucosides are the major classes of spices implicated in augmentation of human health (García-Casal et al., 2016).

There have been proven immune benefits associated with many spices. Carnosol and carnosic acid are the two chief components of rosemary, which have demonstrated anti-HIV activity (Aruoma et al., 1996). Apigenin, a commonly occurring flavonoid present in many spices including thyme, sage, oregano, and rosemary, also have been associated with inhibition of transcription of HIV (Critchfield et al., 1996). Similarly, hydroalcoholic extracts of hyssop had been shown to inhibit HIV activity (Bedoya et al., 2002). Many studies have also demonstrated the antiviral activity of curcumin (Joe et al., 2004, Lin et al., 2005), especially in Herpes Simplex Virus. Curcumin is a yellow polyphenolic curcuminoid obtained from Curcuma longa (turmeric) that possess a wide range of bioactivities including antioxidant, antiapoptotic, and antifibrotic properties with concomitant downregulation of Toll-like receptors, $\mathrm{NF}-\kappa \mathrm{B}$, inflammatory cytokines and chemokines, and bradykinin. Curcumin has been implicated in blocking cellular entry and replication of SARS-CoV-2 and in the repair of pneumocytes, renal cells, cardiomyocytes, and hematopoietic stem cells in the wake of COVID-19 (Soni, Mehta et al. 2020).

Essential oils are also an important class of compounds present in spices with high contents of terpenes, monoterpenes, and sesquiterpenes; compounds that mediate several important physiological functions in our body. The antiviral effect of essential oils, has been reported by many. Eugenol, the principal component of clove bud (Eugenia caryophyllus) was found to possess strong antiviral activity against the types 1 and 2 herpes simplex viruses (HSV-1 and HSV-2) (Benencia and Courreges, 2000). Several nutraceutical formulations based on beneficial spices have also been reported to augment health and well-being. For example, consumption of a milk based drink containing turmeric powder (Golden milk) once or twice a day has been claimed to act as an immune booster, largely by virtue of the active component, curcumin. Curcumin is 
responsible for suppression of anti-inflammatory cytokines and therefore has the potential to arrest a cytokine storm during a coronaviral infection. (Sordillo and Helson, 2015).

\subsection{Molecular basis of the immune augmenting role of spices}

The active ingredients of spices exert their effects by acting as potent anti-oxidants. Their action is mediated mostly by direct or indirect activation of the transcription factor Nuclear factorerythroid factor 2-related factor 2 (Bousquet et al., 2020). Nrf2 is the most potent antioxidant in humans and can minimize oxidative stress arising from both the Renin-Angiotensin II axis as well from the unfolded protein response of endoplasmic reticulum (Bousquet et al., 2020). Upregulation of Nrf2 signalling curbs the secretion of proinflammatory cytokines like IL-6 and also chemokines, and simultaneously downregulates the activation of nuclear factor-kappa $b$ (NFKB). Natural compounds derived from plants, vegetables, fungi, and micronutrients, or physical exercise can activate $\mathrm{Nrf} 2$ (Jiménez-Osorio et al., 2015). The different mortality rates inflicted by COVID-19 in different regions of the world may be partly explained by different culinary habits with differential contents of $\mathrm{Nrf2}$ in the spices used for cooking.

Apart from Nrf-2, another important player in this molecular cross-talk is transient receptor potential (TRP). The TRP vanilloid 1 (TRPV1) and ankyrin 1 (TRPA1) belong to the TRP superfamily of structurally related, nonselective cation channels. They are often co-located in different cell types including sensory neurons, vascular smooth muscle cells, and many immune cells including monocytes and lymphocytes as well as in keratinocytes and epithelial cells, and are implicated in numerous physiological functions (Talavera et al., 2020). These cationic channels are highly sensitive to oxidative damage. Active principles of spices play a major role in preserving the functionality of these molecules and hence ensure maintenance of physiological homeostasis, especially during intrusion by viral and bacterial pathogens.

\subsection{Fatty acids as essential components of functional foods}

The polyunsaturated fatty acids (PUFA) that cannot be synthesized by us, but yet are indispensable are termed 'essential fatty acids' (EFA). EFAs can be categorized into two classes, the omega-3 ( $\omega$ 3 ) fatty acids, which have the last carbon-carbon double bond in the $\omega-3$ position i.e. the third bond from the methyl end of the fatty acid. Omega- $6(\omega-6)$ fatty acids possess a double bond in the $\omega-6$ position i.e. the sixth bond from the methyl end. $\alpha$-Linolenic acid (ALA), eicosapentaenoic acid (EPA), and docosahexaenoic acid (DHA) are the three chief omega-3 ( $\omega-3)$ fatty acids that have been given the designation of functional foods for regulating many physiological processes.Among the omega-6 fatty acids, Linoleic acid,gamma-linolenic acid, dihomo-gamma-linolenic acid, and arachidonic acid are especially worth mentioning with regards to their various functionalities inside the body.

Alpha-linolenic acid is the most readily available $\omega-3$ fatty acid in nature. Its most accessible source are the green leafy vegetables. In addition, alpha-linolenic acid is also found in abundance in flax seed (Hunter, 1990). Fish and fish oil are the most abundant sources of EPA whereas DHA is obtained mostly from fish oil and red brown algae. Safflower, sunflower, and corn are rich sources of linoleic acid. Gamma-linolenic acid is obtained from evening primrose oil, black currant seed oil, and borage oil. Dihomo-gamma-linolenic acid is synthesized from gamma-linolenic acid, and arachidonic acid is present chiefly in meat and dairy sources.

\subsection{Physiological importance of EFAs and their antiviral roles}

Most of the EFAs are incorporated into the phospholipid bilayer and therefore are responsible for the structural integrity of the cell. $\omega-3$ enriched diet is implicated in prevention of cardiovascular diseases (Das, 2000). In fact, the ratio of $\omega-3$ to $\omega-6$ fatty acids plays a significant role in maintaining normal physiological conditions and minimizing development of inflammatory response. Dietary LA is implicated in inflammatory response. However, in the body, LA is desaturated to GLA which is anti-inflammatory. Very recently, EFAs were also demonstrated to inhibit coronaviral pathogenesis by blocking the binding of viral spike protein to ACE2 receptor. Linolenic acid, eicosapentaenoic acid (EPA), and linoleic acid had the highest binding affinity to spikeprotein and hence arrested COVID-19 infection with highest efficiency (Goc et al., 2021).

\subsection{The herbal nutraceuticals}

The term nutraceuticals is an amalgamation of the two words "nutrition" and "pharmaceutical" originally coined in the year 1989 by Stephen Defelice, founder and chairman of the Foundation for Innovation in Medicine (FIM) Cranford, New Jersey (Brower, 1998). Since then, the quest for the extraordinary potential of herbs has flourished and we have come to know about the therapeutic potentials of traditional herbs consumed both as medicines and as culinary delights. Not surprisingly, many such herbs have shown promise to act as effective remedies for both prevention and cure from viral infections, including those caused by SARS-CoV2. The active component present in many of these herbs have been identified and their antiviral potential have been well demonstrated (Table 1). An early study had indicated the anti-coronaviral activity of concanavalin A (conA), a phytagglutinin found in jack beans (Canavalia ensiformis). Since then, many oriental herbs have been discovered with strong antiviral activity. Some of these are Lycorisradiata, Artemisia annua, Pyrrosia lingua, Linderaaggregataetc. which inhibited the viral replication by more than $50 \%$. Houttuynia cordata, an edible herb popularly known as fish mint or rainbow plant, arrested SARS$\mathrm{CoV} 2$ replication by blocking the action of two key viral proteins, chymotrypsin-like protease (3CLpro) and RdRp (Abiri et al., 2021). It also led to increased levels of CD4+ and CD8+ T cells to strengthen the immune system for evading the viral attack (Figure 2).

Herbs of Indian origin belonging to the traditional Ayurveda has been protecting us a plethora of ailments and infections since ages. The treasure trove of Ayurveda has plants from the family polygonaceae inhibiting viral entry into the host (Schwarz et al., 2011), edible herbs like Glycyrrhiza glabra inhibiting viral replication (Cinatl et al., 2003), and plants like Sambucus ebulus arresting viral envelope formation (Choudhary et al., 2020). The AYUSH system maintains a database of these medicinal plants for preserving a systematic knowledge of the diverse repertoire of Indian medicinal plants for effective lifestyle management during the COVID-19 pandemic through lifestyle modification, dietary management as well as prophylactic interventions.

5. Concluding remarks: the future of functional food and nutraceuticals as effective antivirals as compared to traditional medicines

Restoration of physiological homeostasis by functional foods and nutraceuticals is mostly achieved via their anti-inflammatory and antioxidative potential. This to an extent also involves downregu- 
Table 1. : Antiviral effects of some purified molecules of plant origin

\begin{tabular}{|c|c|c|}
\hline Molecule & Target virus and molecule/pathway & Reference \\
\hline Quercetin & SARSCoV, S2 protein & (Colunga Biancatelli et al., 2020) \\
\hline EGCG (Epigallocatechin gallate) & SARSCoV, 3CLPro & (Du et al., 2021) \\
\hline Resveratrol & MERSCOV, NP & (Lin et al., 2017) \\
\hline Wogonin & HSV, host NF-KB and JNK/p38 MAPK pathways & (Chu et al., 2020) \\
\hline Kaempferol & SARS Coronavirus, 3a channel protein & (Schwarz et al., 2014) \\
\hline Luteolin & Influenza A, coat protein I complex & (Yan et al., 2019) \\
\hline Curcumin & Respiratory Syncitial Virus, host NF-KB and JNK/p38 MAPK pathways & (Liu and Ying, 2020) \\
\hline Theaflavin digallate & Herpes Simplex Virus Type 1 & (De Oliveira et al., 2015) \\
\hline Ellagic Acid Derivative & Human Immunodeficiency Virus, CD4 & (Bedoya et al., 2010) \\
\hline Tannic acid & Influenza A virus, Neuraminidase, receptor & (Kaczmarek, 2020) \\
\hline Juglanin & SARS Coronavirus, 3a channel protein & (Schwarz et al., 2014) \\
\hline Rutin & SARS-CoV-2, Main protease & (Abd El-Mordy et al., 2020) \\
\hline Baicalein & Japanase Encephalitis Virus, replication & (Johari et al., 2012) \\
\hline Silymarin & Hepatitis C Virus, & (Ferenci et al., 2008) \\
\hline Genistein & HIV Virus, VPU ion channel & (Sauter et al., 2014) \\
\hline Apigenin & Enterovirus A71, Internal Ribosome Entry Site & (Zhang et al., 2015) \\
\hline Hesperetin & SARSCoV, 3CLPro & (Lin et al., 2005) \\
\hline
\end{tabular}

lation of the immune arsenal involving activation of CTL, macrophages, NK cells and many others. Therefore, the applicability of these products seems to be more suitable to accelerate post infection recovery or as prophylactics rather than targeted therapeu- tics to combat the spread of the virus. It is for this reason, that the commercial exploitation of many of the herbal and other products mentioned in this review has either not been initiated or has failed to make a mark. However, this in no way deters the scope and
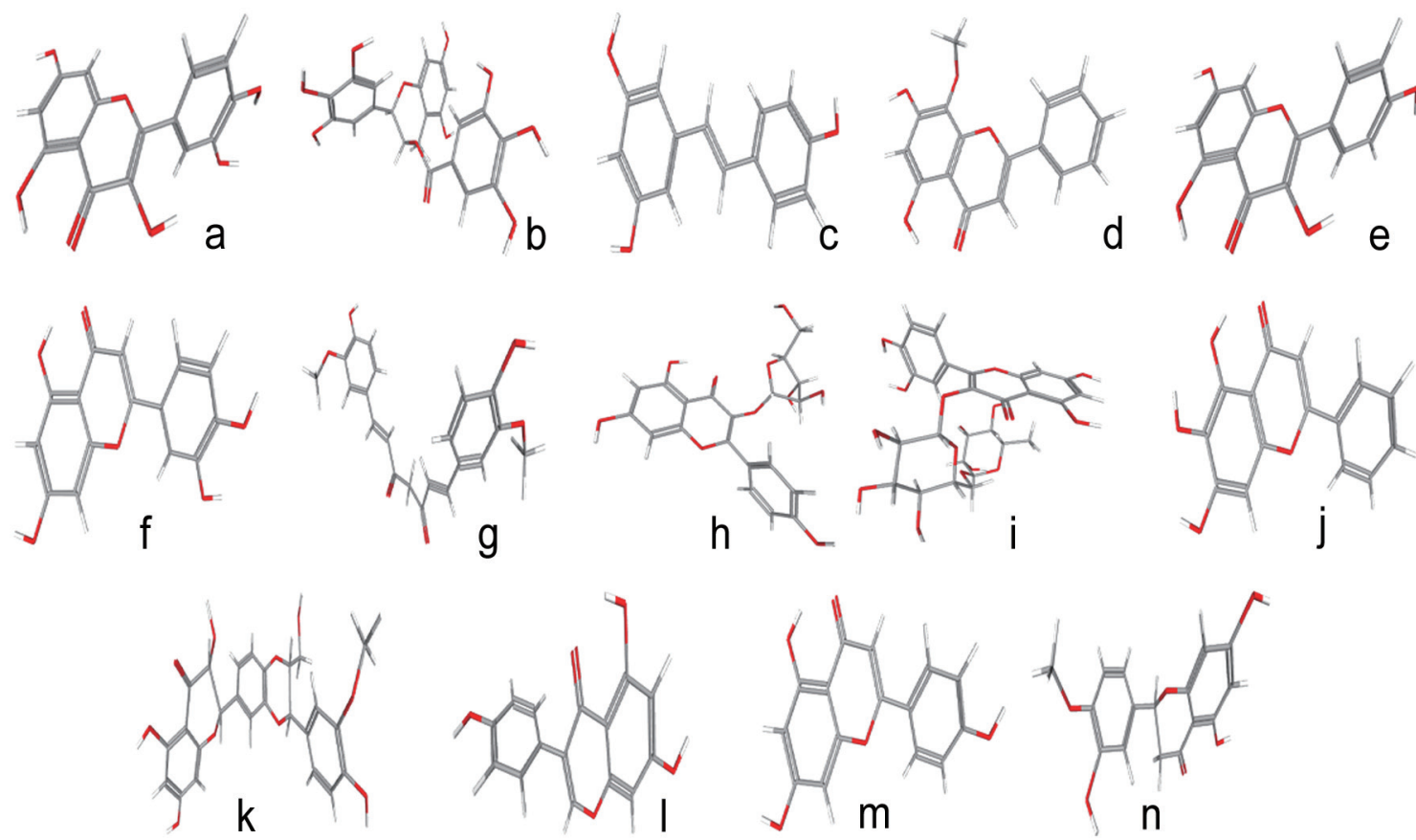

Figure 2. Some important phytochemicals available in medicinal herbs, nutraceuticals and functional foods along with their Pubchem IDs A) Quercetin, 5280343 B) Epigallocatechin gallate, 65064 C) Resveratrol, 445154 D) Wogonin, 5281703 E) Kaempferol, 5280863 F) Luteolin, 5280445 G) Curcumin, 969516 H) Juglanin, 5318717 I) Rutin, 5280805 J) Baicalein, 5281605 K) Silymarin, 5213 L) Genistein, 5280961 M) Apigenin, 5280443 N) Hesperetin, 72281. 
applicability of functional foods since their future is bright and ever-expanding with so many unexplored components. Additionally, these compounds have proven to be much safer as compared to the corresponding synthetic molecules making them especially more popular for paediatric use. Therefore, if a dual impetus of funding and systematic research is put into this field, the future of functional foods and nutraceuticals will shine brighter than synthetic drug research.

\section{References}

Abd El-Mordy, F.M., El-Hamouly, M.M., Ibrahim, M.T., Abd El-Rheem, G., Aly, O.M., Abd El-Kader, A.M., Youssif, K.A., and Abdelmohsen, U.R. (2020). Inhibition of SARS-CoV-2 main protease by phenolic compounds from Manilkara hexandra (Roxb.) Dubard assisted by metabolite profiling and in silico virtual screening. RSC Adv. 10: 32148-3215.

Abiri, R., Abdul-Hamid, H., Sytar, O., Abiri, R., Bezerra De Almeida, E., Sharma, S.K., Bulgakov, V.P., Arroo, R.R., and Malik, S. (2021). A Brief Overview of Potential Treatments for Viral Diseases Using Natural Plant Compounds: The Case of SARS-Cov. Molecules 26: 3868.

Ahmed, S.F., Quadeer, A.A., and Mckay, M.R. (2020). Preliminary identification of potential vaccine targets for the COVID-19 coronavirus (SARS-CoV-2) based on SARS-CoV immunological studies. Viruses 12 254.

Annunziata, G., Jiménez-García, M., Capó, X., Moranta, D., Arnone, A., Tenore, G., Sureda, A., and Tejada, S. (2020). Microencapsulation as a tool to counteract the typical low bioavailability of polyphenols in the management of diabetes. Food Chem. Toxicol. 139: 111248.

Aruoma, O., Spencer, J., Rossi, R., Aeschbach, R., Khan, A., Mahmood, N., Munoz, A., Murcia, A., Butler, J., and Halliwell, B. (1996). An evaluation of the antioxidant and antiviral action of extracts of rosemary and Provencal herbs. Food Chem. Toxicol. 34: 449-456.

Bach, J.-F., and Dardenne, M. (1989). Thymulin, a zinc-dependent hormone. Med. Oncol. Tumor. Pharmacother. 6: 25-29.

Beard, J.A., Bearden, A., and Striker, R. (2011). Vitamin D and the anti-viral state. J. Clin. Virol. 50: 194-200.

Bedoya, L., Abad, M., Sánchez-Palomino, S., Alcami, J., and Bermejo, P. (2010). Ellagitannins from Tuberaria lignosa as entry inhibitors of HIV. Phytomedicine 17: 69-74.

Bedoya, L., Palomino, S.S., Abad, M., Bermejo, P., and Alcami, J. (2002). Screening of selected plant extracts for in vitro inhibitory activity on human immunodeficiency virus. Phytother. Res. 16: 550-554.

Benencia, F., and Courreges, M. (2000). In vitro and in vivo activity of eugenol on human herpesvirus. Phytother. Res. 14: 495-500.

Bertelli, C., Pillonel, T., Torregrossa, A., Prod'hom, G., Fischer, C.J., Greub, G., and Giannoni, E. (2015). Bifidobacterium longum bacteremia in preterm infants receiving probiotics. Clin. Infect. Dis. 60: 924-927.

Bikle, D.D. (2014). Vitamin D metabolism, mechanism of action, and clinical applications. Chem. Biol. 21: 319-329.

Bikle, D.D., Ng, D., Oda, Y., Hanley, K., Feingold, K., and Xie, Z. (2002). The vitamin $D$ response element of the involucrin gene mediates its regulation by 1 , 25-dihydroxyvitamin D3. J. Invest. Dermatol. 119: 1109-1113.

Bousquet, J., Cristol, J.P., Czarlewski, W., Anto, J.M., Martineau, A., Haahtela, T., Fonseca, S.C., laccarino, G., Blain, H., and Fiocchi, A. (2020). Nrf2-interacting nutrients and COVID-19: time for research to develop adaptation strategies. Clin. Transl. Allergy 10: 58.

Brower, V. (1998). Nutraceuticals: poised for a healthy slice of the healthcare market? Nat. Biotechnol. 16: 728-731.

Busso, N., Wagtmann, N., Herling, C., Chobaz-Péclat, V., Bischof-Delaloye, A., So, A., and Grouzmann, E. (2005). Circulating CD26 is negatively associated with inflammation in human and experimental arthritis. Am. J. Pathol. 166: 433-442.

Butterworth, B.E., and Korant, B.D. (1974). Characterization of the large picornaviral polypeptides produced in the presence of zinc ion. J Virol. 14: 282-291.

Carabotti, M., Scirocco, A., Maselli, M.A., and Severi, C. (2015). The gutbrain axis: interactions between enteric microbiota, central and en- teric nervous systems. Ann. Gastroenterol. 28: 203

Carlson, A.L., Xia, K., Azcarate-Peril, M.A., Goldman, B.D., Ahn, M., Styner, M.A., Thompson, A.L., Geng, X., Gilmore, J.H., and Knickmeyer, R.C. (2018). Infant gut microbiome associated with cognitive development. Biol. Psychiatry 83: 148-159.

Cebula, A., Seweryn, M., Rempala, G.A., Pabla, S.S., Mcindoe, R.A., Denning, T.L., Bry, L., Kraj, P., Kisielow, P., and Ignatowicz, L. (2013). Thy mus-derived regulatory T cells contribute to tolerance to commensal microbiota. Nature 497: 258-262.

Chandra, R.K. (1996). Nutrition, immunity and infection: from basic knowledge of dietary manipulation of immune responses to practical ap plication of ameliorating suffering and improving survival. Proc. Natl. Acad. Sci. USA 93: 14304-14307.

Chen, C., Zuckerman, D.M., Brantley, S., Sharpe, M., Childress, K., Hoiczyk, E., and Pendleton, A.R. (2014). Sambucus nigra extracts inhibit infectious bronchitis virus at an early point during replication. BMC Vet. Res. 10: 1-12.

Choudhary, N., Lodha, M., and Baranwal, V. (2020). The role of enzymatic activities of antiviral proteins from plants for action against plant pathogens. 3 Biotech 10: 505.

Christakos, S., Dhawan, P., Verstuyf, A., Verlinden, L., and Carmeliet, G. (2016). Vitamin D: metabolism, molecular mechanism of action, and pleiotropic effects. Physiol. Rev. 96: 365-408.

Chu, Y., Lv, X., Zhang, L., Fu, X., Song, S., Su, A., Chen, D., Xu, L., Wang, Y., and $\mathrm{Wu}, \mathrm{Z}$. (2020). Wogonin inhibits in vitro herpes simplex virus type 1 and 2 infection by modulating cellular NF-KB and MAPK pathways. BMC Microbiol. 20: 1-11.

Cinatl, J., Morgenstern, B., Bauer, G., Chandra, P., Rabenau, H., and Doerr H. (2003). Glycyrrhizin, an active component of liquorice roots, and replication of SARS-associated coronavirus. Lancet 361: 2045-2046.

Colunga Biancatelli, R.M.L., Berrill, M., Catravas, J.D., and Marik, P.E. (2020). Quercetin and vitamin C: an experimental, synergistic therapy for the prevention and treatment of SARS-CoV-2 related disease (COVID-19). Front. Immunol. 11: 1451

Connolly, M., Tuohy, K., and Lovegrove, J. (2012). Wholegrain oat-based cereals have prebiotic potential and low glycaemic index. Br. J. Nutr. 108: 2198-2206.

Critchfield, J.W., Butera, S.T., and Folks, T.M. (1996). Inhibition of HIV activation in latently infected cells by flavonoid compounds. AIDS Res. Hum. Retroviruses 12: 39-46.

Cui, J., Li, F., and Shi, Z.-L. (2019). Origin and evolution of pathogenic coronaviruses. Nat. Rev. Microbiol. 17: 181-192.

Cummings, J.H., Macfarlane, G.T., and Englyst, H.N. (2001). Prebiotic digestion and fermentation. Am. J. Clin. Nutr. 73: 415s-420s.

Dang, A.T., and Marsland, B.J. (2019). Microbes, metabolites, and the gutlung axis. Mucosal Immunol. 12: 843-850.

Das, U.N. (2000). Beneficial effect (s) of n-3 fatty acids in cardiovascular diseases: but, why and how? Prostaglandins Leukot. Essent. Fatty Acids 63: $351-362$.

De Oliveira, A., Prince, D., Lo, C.-Y., Lee, L.H., and Chu, T.-C. (015). Antiviral activity of theaflavin digallate against herpes simplex virus type 1 . Antiviral Res. 118: 56-67.

Delesderrier, E., Cople-Rodrigues, C.S., Omena, J., Kneip Fleury, M., Barbosa Brito, F., Costa Bacelo, A., Correa Koury, J., and Citelli, M. (2019). Selenium status and hemolysis in sickle cell disease patients. Nutrients 11: 2211.

Dermyshi, E., Wang, Y., Yan, C., Hong, W., Qiu, G., Gong, X., and Zhang, T. (2017). The "golden age" of probiotics: a systematic review and meta-analysis of randomized and observational studies in preterm infants. Neonatology 112: 9-23.

Diebold, S.S., Kaisho, T., Hemmi, H., Akira, S., and E Sousa, C.R. (2004). Innate antiviral responses by means of TLR7-mediated recognition of single-stranded RNA. Science 303: 1529-1531.

Du, A., Zheng, R., Disoma, C., Li, S., Chen, Z., Li, S., Liu, P., Zhou, Y., Shen, Y., and Liu, S. (2021). Epigallocatechin-3-gallate, an active ingredient of Traditional Chinese Medicines, inhibits the 3CLpro activity of SARS CoV-2. Int. J. Biol. Macromol. 176: 1-12.

Faith, S.A., Sweet, T.J., Bailey, E., Booth, T., and Docherty, J.J. (006). Resveratrol suppresses nuclear factor-KB in herpes simplex virus infected cells. Antiviral Res. 72: 242-251.

Fassina, G., Buffa, A., Benelli, R., Varnier, O.E., Noonan, D.M., and Albini, A. 
(2002). Polyphenolic antioxidant (-)-epigallocatechin-3-gallate from green tea as a candidate anti-HIV agent. Aids 16: 939-941.

Ferenci, P., Scherzer, T.M., Kerschner, H., Rutter, K., Beinhardt, S., Hofer, H., Schöniger-Hekele, M., Holzmann, H., and Steindl-Munda, P. (2008). Silibinin is a potent antiviral agent in patients with chronic hepatitis $C$ not responding to pegylated interferon/ribavirin therapy. Gastroenterology 135: 1561-1567.

Ferrari, E., Wright-Minogue, J., Fang, J.W., Baroudy, B.M., Lau, J.Y., and Hong, Z. (1999). Characterization of soluble hepatitis C virus RNAdependent RNA polymerase expressed in Escherichia coli. J Virol. 73: 1649-1654.

Fogarty, H., Townsend, L., Cheallaigh, C.N., Bergin, C., Martin-Loeches, I., Browne, P., Bacon, C.L., Gaule, R., Gillett, A., Byrne, M., Ryan, K., O'Connell, N., O'Sullivan, J.M., Conlon, N., and O'Donnell, J.S. (2020). COVID-19 coagulopathy in caucasian patients. Br. J. Haematol. 189: 1044-1049.

Frei, R., Akdis, M., and O'mahony, L. (2015). Prebiotics, probiotics, synbiotics, and the immune system: experimental data and clinical evidence. Curr. Opin. Gastroenterol. 31: 153-158.

Fridlender, B., Chejanovsky, N., and Becker, Y. (1978). Selective inhibition of herpes simplex virus type 1 DNA polymerase by zinc ions. Virology 84: 551-554.

García-Casal, M.N., Peña-Rosas, J.P., and Malavé, H.G. (2016). Sauces, spices, and condiments: definitions, potential benefits, consumption patterns, and global markets. Ann. N. Y. Acad. Sci. 1379: 3-16.

Goc, A., Niedzwiecki, A., and Rath, M. (2021). Polyunsaturated $\omega-3$ fatty acids inhibit ACE2-controlled SARS-CoV-2 binding and cellular entry. Sci. Rep. 11: 1-12.

Gordon, J.I., Dewey, K.G., Mills, D.A., and Medzhitov, R.M. (2012). The human gut microbiota and undernutrition. Sci. Transl. Med. 4: 137ps12-137ps12.

Guarino, M.P.L., Altomare, A., Emerenziani, S., Di Rosa, C., Ribolsi, M., Balestrieri, P., lovino, P., Rocchi, G., and Cicala, M. (2020). Mechanisms of action of prebiotics and their effects on gastro-intestinal disorders in adults. Nutrients 12: 1037

Hao, Q., Dong, B.R., and Wu, T. (2015). Probiotics for preventing acute upper respiratory tract infections. Cochrane Database Syst. Rev. (1): CD006895.

Holick, M.F., Maclaughlin, J., Clark, M., Holick, S., Potts, J., Anderson, R., Blank, I., Parrish, J., and Elias, P. (1980). Photosynthesis of previtamin D3 in human skin and the physiologic consequences. Science 210: 203-205.

Hunter, J.E. (1990). n-3 fatty acids from vegetable oils. Am. J. Clin. Nutr. 51: 809-814.

Ibs, K.-H., and Rink, L. (2003). Zinc-altered immune function. J. Nutr. 133: 1452S-1456S

Imanishi, N., Tuji, Y., Katada, Y., Maruhashi, M., Konosu, S., Mantani, N., Terasawa, K., and Ochiai, H. (2002). Additional inhibitory effect of tea extract on the growth of influenza A and B viruses in MDCK cells. Microbiol Immunol. 46: 491-494.

Jayawardena, R., Sooriyaarachchi, P., Chourdakis, M., Jeewandara, C., and Ranasinghe, P. (2020). Enhancing immunity in viral infections, with special emphasis on COVID-19: A review. Diabetes Metab. Syndr. 14: 367-382.

Jiménez-Osorio, A.S., Gonzalez-Reyes, S., and Pedraza-Chaverri, J. (2015). Natural Nrf2 activators in diabetes. Clin. Chim. Acta 448: 182-192.

Joe, B., Vijaykumar, M., and Lokesh, B. (2004). Biological properties of curcumin-cellular and molecular mechanisms of action. Crit. Rev. Food Sci. Nutr. 44: 97-111.

Johari, J., Kianmehr, A., Mustafa, M.R., Abubakar, S., and Zandi, K. (2012). Antiviral activity of baicalein and quercetin against the Japanese encephalitis virus. Int. J. Mol. Sci. 13: 16785-16795.

Kaczmarek, B. (2020). Tannic acid with antiviral and antibacterial activity as a promising component of biomaterials - A minireview. Materials 13: 3224.

Kanauchi, O., Andoh, A., Abubakar, S., and Yamamoto, N. (2018). Probiotics and paraprobiotics in viral infection: clinical application and effects on the innate and acquired immune systems. Curr. Pharm. Des. 24: 710-717.

Kieliszek, M., and Lipinski, B. (2020). Selenium supplementation in the prevention of coronavirus infections (COVID-19). Med. Hypotheses.
143: 109878

Kiremidjian-Schumacher, L., and Roy, M. (1998). Selenium and immune function. Zeitschrift fur Ernahrungswissenschaft 37: 50-56.

Lange, K.W. (2021). Food science and COVID-19. Food Sci. Hum. Wellness 10: $1-5$.

Lazar, V., Ditu, L.-M., Pircalabioru, G.G., Gheorghe, I., Curutiu, C., Holban, A.M., Picu, A., Petcu, L., and Chifiriuc, M.C. (2018). Aspects of gut microbiota and immune system interactions in infectious diseases, immunopathology, and cancer. Front. Immunol. 9: 1830.

Li, W., Moore, M.J., Vasilieva, N., Sui, J., Wong, S.K., Berne, M.A., Somasundaran, M., Sullivan, J.L., Luzuriaga, K., and Greenough, T.C. (2003). Angiotensin-converting enzyme 2 is a functional receptor for the SARS coronavirus. Nature 426: 450-454.

Li, Y., Dong, J., Xiao, H., Zhang, S., Wang, B., Cui, M., and Fan, S. (2020). Gut commensal derived-valeric acid protects against radiation injuries. Gut Microbes 11: 789-806.

Lin, C.-J., Lin, H.-J., Chen, T.-H., Hsu, Y.-A., Liu, C.-S., Hwang, G.-Y., and Wan, L. (2015). Polygonum cuspidatum and its active components inhibit replication of the influenza virus through toll-like receptor 9-induced interferon beta expression. PLoS One 10: e0117602.

Lin, C.-W., Tsai, F.-J., Tsai, C.-H., Lai, C.-C., Wan, L., Ho, T.-Y., Hsieh, C.-C., and Chao, P.-D.L. (2005). Anti-SARS coronavirus 3C-like protease effects of Isatis indigotica root and plant-derived phenolic compounds. Antiviral Res. 68: 36-42.

Lin, S.-C., Ho, C.-T., Chuo, W.-H., Li, S., Wang, T.T., and Lin, C.-C. (2017). Effective inhibition of MERS-CoV infection by resveratrol. BMC Infect. Dis. 17: 1-10.

Liu, Z., and Ying, Y. (2020). The inhibitory effect of curcumin on virus-induced cytokine storm and its potential use in the associated severe pneumonia. Front. Cell Dev. Biol. 8: 479.

López-Varela, S., González-Gross, M., and Marcos, A. (2002). Functional foods and the immune system: a review. Eur. J. Clin. Nutr. 56: S29S33.

Loser, K., and Beissert, S. (2009). Regulation of cutaneous immunity by the environment: an important role for UV irradiation and vitamin D. Int. Immunopharmacol. 9: 587-589.

Martineau, A.R., Jolliffe, D.A., Hooper, R.L., Greenberg, L., Aloia, J.F., Bergman, P., Dubnov-Raz, G., Esposito, S., Ganmaa, D., and Ginde, A.A. (2017). Vitamin D supplementation to prevent acute respiratory tract infections: systematic review and meta-analysis of individual participant data. BMJ 356: i6583.

Martirosyan, D.M., and Singh, J. (2015). A new definition of functional food by FFC: what makes a new definition unique? Funct. Foods Health Dis. 5: 209-223.

Meng, X., Zhou, J., Zhao, C.-N., Gan, R.-Y., and Li, H.-B. (2020). Health benefits and molecular mechanisms of resveratrol: A narrative review. Foods 9: 340 .

Messina, G., Polito, R., Monda, V., Cipolloni, L., Di Nunno, N., Di Mizio, G., Murabito, P., Carotenuto, M., Messina, A., and Pisanelli, D. (2020). Functional role of dietary intervention to improve the outcome of COVID-19: a hypothesis of work. Int. J. Mol. Sci. 21: 3104.

Mirzaei, R., Attar, A., Papizadeh, S., Jeda, A.S., Hosseini-Fard, S.R., Jamasbi, E., Kazemi, S., Amerkani, S., Talei, G.R., and Moradi, P. (2021). The emerging role of probiotics as a mitigation strategy against coronavirus disease 2019 (COVID-19). Arch. Virol. 166: 1819-1840.

Nagpal, R., Shively, C.A., Register, T.C., Craft, S., and Yadav, H. (2019). Gut microbiome-Mediterranean diet interactions in improving host health. F1000Research 8: 699.

Nakayama, M., Suzuki, K., Toda, M., Okubo, S., Hara, Y., and Shimamura, T. (1993). Inhibition of the infectivity of influenza virus by tea polyphenols. Antiviral Res. 21: 289-299.

Nicoletti, M. (2012). Nutraceuticals and botanicals: overview and perspectives. Int. J. Food Sci. Nutr. 63: 2-6.

Opara, E.C. (2002). Oxidative stress, micronutrients, diabetes mellitus and its complications. J. R. Soc. Promot. Health. 122: 28-34.

Palamara, A.T., Nencioni, L., Aquilano, K., De Chiara, G., Hernandez, L., Cozzolino, F., Ciriolo, M.R., and Garaci, E. (2005). Inhibition of influenza A virus replication by resveratrol. J. Infect. Dis. 191: 1719-1729.

Pannu, N., and Bhatnagar, A. (2019). Resveratrol: From enhanced biosynthesis and bioavailability to multitargeting chronic diseases. Biomed. Pharmacother. 109: 2237-2251. 
Pavan, R., Jain, S., and Kumar, A. (2012). Properties and therapeutic application of bromelain: a review. Biotechnol. Res. Int. 2012: 976203.

Pimentel-Nunes, P., Soares, J.B., Roncon-Albuquerque, R., Dinis-Ribeiro, M., and Leite-Moreira, A.F. (2010). Toll-like receptors as therapeutic targets in gastrointestinal diseases. Expert Opin. Ther. Targets 14: 347-368.

Rahman, M.T., and Idid, S.Z. (2021). Can Zn be a critical element in COVID-19 treatment? Biol. Trace Elem. Res. 199: 550-558.

Rayman, M.P. (2000). The importance of selenium to human health. Lancet 356: $233-241$.

Reygaert, W.C. (2018). Green tea catechins: Their use in treating and preventing infectious diseases. BioMed Res. Int. 2018: 9105261.

Ru-Duan, W., Chang-Sen, W., Zuo-Hua, F., and Yi, L. (1992). Investigation on the effect of selenium on T lymphocyte proliferation and its mechanisms. J. Tongji Med. Univ. 12: 33-38.

Sargiacomo, C., Sotgia, F., and Lisanti, M.P. (2020). COVID-19 and chronological aging: senolytics and other anti-aging drugs for the treatment or prevention of corona virus infection? Aging (Albany NY) 12: 6511.

Sauter, D., Schwarz, S., Wang, K., Zhang, R., Sun, B., and Schwarz, W. (2014). Genistein as antiviral drug against HIV ion channel. Planta Med. 80: 682-687.

Scholz-Ahrens, K.E., Ade, P., Marten, B., Weber, P., Timm, W., Açil, Y., Glüer, C.-C., and Schrezenmeir, J.R. (2007). Prebiotics, probiotics, and synbiotics affect mineral absorption, bone mineral content, and bone structure. J. Nutr. 137: 838S-846S.

Schuetz, P., Fehr, R., Baechli, V., Geiser, M., Deiss, M., Gomes, F., Kutz, A., Tribolet, P., Bregenzer, T., and Braun, N. (2019). Individualised nutritional support in medical inpatients at nutritional risk: a randomised clinical trial. Lancet 393: 2312-2321.

Schwarz, S., Sauter, D., Wang, K., Zhang, R., Sun, B., Karioti, A., Bilia, A.R., Efferth, T., and Schwarz, W. (2014). Kaempferol derivatives as antiviral drugs against the 3a channel protein of coronavirus. Planta Med. 80: $177-182$.

Schwarz, S., Wang, K., Yu, W., Sun, B., and Schwarz, W. (2011). Emodin inhibits current through SARS-associated coronavirus 3a protein. Antiviral Res. 90: 64-69.

Shaito, A., Posadino, A.M., Younes, N., Hasan, H., Halabi, S., Alhababi, D., Al-Mohannadi, A., Abdel-Rahman, W.M., Eid, A.H., and Nasrallah, G.K. (2020). Potential adverse effects of resveratrol: A literature review. Int. J. Mol. Sci. 21: 2084

Shang, J., Wan, Y., Liu, C., Yount, B., Gully, K., Yang, Y., Auerbach, A., Peng, G., Baric, R., and Li, F. (2020). Structure of mouse coronavirus spike protein complexed with receptor reveals mechanism for viral entry. PLoS Pathog. 16: e1008392.

Sharma, R.K., Goswami, B., Mandal, S.D., Guha, A., Willard, B., and Ray, P.S. (2021). Quorum Sensing by Gelsolin Regulates Programmed Cell Death 4 Expression and a Density-Dependent Phenotype in Macrophages. J. Immunol. 207: 1250-1264.

Sindona, C., Schepici, G., Contestabile, V., Bramanti, P., and Mazzon, E. (2021). NOX2 Activation in COVID-19: Possible Implications for Neurodegenerative Diseases. Medicina (Kaunas) 57: 604.

Somerville, V.S., Braakhuis, A.J., and Hopkins, W.G. (2016). Effect of flavonoids on upper respiratory tract infections and immune function: a systematic review and meta-analysis. Adv. Nutr. 7: 488-497.

Song, J.-M., Lee, K.-H., and Seong, B.-L. (2005). Antiviral effect of catechins in green tea on influenza virus. Antiviral Res. 68: 66-74.

Soni, V.K., Mehta, A., Ratre, Y.K., Tiwari, A.K., Amit, A., Singh, R.P., Sonkar, S.C., Chaturvedi, N., Shukla, D., and Vishvakarma, N.K. (2020). Curcumin, a traditional spice component, can hold the promise against COVID-19? Eur. J. Pharmacol. 886: 173551.

Sordillo, P.P., and Helson, L. (2015). Curcumin suppression of cytokine release and cytokine storm. A potential therapy for patients with Ebola and other severe viral infections. In Vivo 29: 1-4.

Subramanian, V.K., and Deepe, G.S. (2017). Metallothioneins: emerging modulators in immunity and infection. Int. J. Mol. Sci. 18: 2197.

Szczepanski, A., Owczarek, K., Bzowska, M., Gula, K., Drebot, I., Ochman, M., Maksym, B., Rajfur, Z., Mitchell, J.A., and Pyrc, K. (2019). Canine respiratory coronavirus, bovine coronavirus, and human coronavirus OC43: receptors and attachment factors. Viruses 11: 328

Talavera, K., Startek, J.B., Alvarez-Collazo, J., Boonen, B., Alpizar, Y.A.,
Sanchez, A., Naert, R., and Nilius, B. (2020). Mammalian transient receptor potential TRPA1 channels: from structure to disease. Physiol. Rev. 100: 725-803.

Tang, N.L.-S., Chan, P.K.-S., Wong, C.-K., To, K.-F., Wu, A.K.-L., Sung, Y.-M., Hui, D.S.-C., Sung, J.J.-Y., and Lam, C.W.-K. (2005). Early enhanced expression of interferon-inducible protein-10 (CXCL-10) and other chemokines predicts adverse outcome in severe acute respiratory syndrome. Clin. Chem. 51: 2333-2340.

Tapiovaara, L., Pitkäranta, A.I., and Korpela, R. (2016). Probiotics and upper respiratory tract - a review. Pediatr. Infect. Dis. 1: 19

Te Velthuis, A.J., Van Den Worm, S.H., Sims, A.C., Baric, R.S., Snijder, E.J., and Van Hemert, M.J. (2010). $\mathrm{Zn}^{2+}$ inhibits coronavirus and arterivirus RNA polymerase activity in vitro and zinc ionophores block the replication of these viruses in cell culture. PLoS Pathog. 6: e1001176.

Tikellis, C., and Thomas, M. (2012). Angiotensin-converting enzyme 2 (ACE2) is a key modulator of the renin angiotensin system in health and disease. Int. J. Pept. 2012: 256294

Trichopoulou, A., Costacou, T., Bamia, C., and Trichopoulos, D. (2003). Adherence to a Mediterranean diet and survival in a Greek population. N. Engl. J. Med. 348: 2599-2608.

Valdés-Ramos, R., Martínez-Carrillo, B.E., Aranda-González, I.I., Guadarrama, A.L., Pardo-Morales, R.V., Tlatempa, P., and Jarillo-Luna, R.A. (2010). Diet, exercise and gut mucosal immunity. Proc. Nutr. Soc. 69: 644-650.

Vankadari, N., and Wilce, J.A. (2020). Emerging COVID-19 coronavirus: glycan shield and structure prediction of spike glycoprotein and its in teraction with human CD26. Emerging Microbes Infect. 9: 601-604.

Wen, F., Yu, H., Guo, J., Li, Y., Luo, K., and Huang, S. (2020). Identification of the hyper-variable genomic hotspot for the novel coronavirus SARSCoV-2. J. Infect. 80: 671.

Wilson, B., Rossi, M., Dimidi, E., and Whelan, K. (2019). Prebiotics in irritable bowel syndrome and other functional bowel disorders in adults: a systematic review and meta-analysis of randomized controlled trials. Am. J. Clin. Nutr. 109: 1098-1111.

Wintergerst, E.S., Maggini, S., and Hornig, D.H. (2007). Contribution of selected vitamins and trace elements to immune function. Ann. Nutr. Metab. 51: 301-323.

Xu, K., Cai, H., Shen, Y., Ni, Q., Chen, Y., Hu, S., Li, J., Wang, H., Yu, L., and Huang, H. (2020). Management of COVID-19: the Zhejiang experience. J. Zhejiang Univ. Sci. 49: 147-157.

Yahfoufi, N., Alsadi, N., Jambi, M., and Matar, C. (2018). The immunomodulatory and anti-inflammatory role of polyphenols. Nutrients 10 1618

Yan, H., Ma, L., Wang, H., Wu, S., Huang, H., Gu, Z., Jiang, J., and Li, Y. (2019). Luteolin decreases the yield of influenza A virus in vitro by interfering with the coat protein I complex expression. J. Nat. Med. 73: 487-496.

Yang, F., Zhang, Y., Tariq, A., Jiang, X., Ahmed, Z., Zhihao, Z., Idrees, M., Azizullah, A., Adnan, M., and Bussmann, R.W. (2020). Food as medicine: A possible preventive measure against coronavirus disease (COVID-19). Phytother. Res. 34: 3124-3136.

Yaqoob, P. (2017). Ageing alters the impact of nutrition on immune function. Proc. Nutr. Soc. 76: 347-351.

Yi, H., Wang, L., Xiong, Y., Wang, Z., Qiu, Y., Wen, X., Jiang, Z., Yang, X., and $\mathrm{Ma}, \mathrm{X}$. (2018). Lactobacillus reuteri LR1 improved expression of genes of tight junction proteins via the MLCK pathway in IPEC-1 cells during infection with enterotoxigenic Escherichia coli K88. Mediators Inflamm. 2018: 6434910

Yiu, C.-Y., Chen, S.-Y., Chang, L.-K., Chiu, Y.-F., and Lin, T.-P. (2010). Inhibitory effects of resveratrol on the Epstein-Barr virus lytic cycle. Molecules 15: 7115-7124.

Zang, N., Xie, X., Deng, Y., Wu, S., Wang, L., Peng, C., Li, S., Ni, K., Luo, Y., and Liu, E. (2011). Resveratrol-mediated gamma interferon reduction prevents airway inflammation and airway hyperresponsiveness in respiratory syncytial virus-infected immunocompromised mice. $J$ Virol. 85: 13061-13068.

Zhang, L., Li, Y., Gu, Z., Wang, Y., Shi, M., Ji, Y., Sun, J., Xu, X., Zhang, L., and Jiang, J. (2015). Resveratrol inhibits enterovirus 71 replication and pro-inflammatory cytokine secretion in rhabdosarcoma cells through blocking IKKs/NF-KB signaling pathway. PLoS One 10: e0116879. 